\title{
Perceptions of Religious Discrimination among US Scientists
}

CHRISTOPHER P. SCHEITLE

Department of Sociology and Anthropology

West Virginia University

\section{ELAINE HOWARD ECKLUND}

Department of Sociology

Rice University

Academic scientists in the US are relatively non-religious, at least compared to the general population, and some evidence suggests that the professional culture of academic science may foster perceptions of discrimination among scientists who are religious. We examine perceptions of religious discrimination among biologists and physicists in the United States. The analysis shows that Protestant, Muslim, and adherents of 'other' traditions report higher rates of religious discrimination in both biology and physics relative to those who do not identify with a religion. Jewish and Catholic adherents report higher rates of discrimination in biology but not physics. Most of the religious identity effects among biologists are not explained away by measures of beliefs, practices, or professional and demographic characteristics. On the other hand, religious identity differences in perceptions of religious discrimination among physicists are mediated by measures of religious practice. On the whole, these findings suggest that religious identity itself is more stigmatized in biology than in physics. Results have implications for how university professors - and academic scientists in particular - relate to the broader public.

Keywords: science, discrimination, workplaces, scientists, religion. 
Note: Data Collection was funded by a grant from the Templeton World Charity Foundation (Grant \#0033/AB14), Elaine Howard Ecklund, PI, Kirstin R.W. Matthews and Steven W. Lewis, co-PIs

Correspondence should be addressed to Christopher P. Scheitle, Department of Sociology and Anthropology, West Virginia University, PO Box 6326, Morgantown, WV, 26506. Phone: (304)293-8812.E-Mail: cpscheitle@ mail.wvu.edu 
PERCEPTIONS OF RELIGIOUS DISCRIMINATION

\section{INTRODUCTION}

Research has shown that US academic scientists are significantly less religious than the general US population. Ecklund's (2010) survey of scientists working in twenty-one US elite research universities, for example, found that $53 \%$ did not identify with a religion and $34 \%$ stated unequivocally that they do not believe in God. This compares to $16 \%$ and $2 \%$ in the general population according to similarly-timed General Social Surveys. Academic scientists'

irreligiosity is, in part, reflective of the academic population as a whole, but Gross and Simmons (2009) found that not believing in God was more common among engineering, computer science, social science, and natural science professors compared to professors in fields such as business, education, and health-related disciplines. This suggests that science-related academics - and perhaps, in particular those who teach and do research at top US universities -- are particularly unique in having lower levels of religiosity.

Of course, there are scientists who are religious. For such scientists, the general lack of religion among academic scientists could present a challenging environment. Beyond being in the minority vis-à-vis religiosity, religious scientists could face a workplace culture that is antagonistic towards religion. Some evidence of this culture is anecdotal. For example, when outspoken Christian Francis Collins was appointed to be the director of the National Institutes of Health, a New York Times profile mentioned that "many scientists view such outspoken religious commitment as a sign of mild dementia" (Harris 2009). The article quotes several scientists concerned about having a devout Christian lead a scientific agency.

Bolstering such anecdotal evidence is research showing that at least some religious groups are stereotyped in the general public as being hostile towards and even less competent in science. For instance, Rios, Cheng, Totton, and Shariff (2015) found that non-Christians and 
non-religious individuals, whom are prominent among academic scientists, view Christians as being less competent in science. Interestingly, even Christians in this study recognized that they are perceived as being less competent in science, although they did not personally agree with this stereotype.

Such findings suggest that religious scientists could encounter actual cases of discrimination and even hostility towards their faith in the scientific workplace. At the very least, religious scientists might fear or worry about such encounters. These fears could, in turn, lead religious scientists to perceive discrimination and hostility even if it might not objectively exist. Indeed, research has shown that individuals who believe that others are hostile towards them can perceive hostility in others' words and actions even when it does not actually exist (Aquino, Grover, Bradfield, and Allen 1999; Bowling and Beehr 2006).

In this research we examine perceptions of religious discrimination in the workplace among biologists and physicists in the United States. We utilize an original survey of biologists and physicists working in universities or research institutions. Before discussing our measures and analysis further, though, we situate this research within previous literature on religious discrimination in the workplace and discuss the specific dynamics that could shape religious discrimination among academic scientists.

\section{Workplace Religious Discrimination: Experiments and Surveys}

Compared to race, sex, age, and other factors, there has been comparatively little research on the prevalence or impact of religious discrimination in the workplace. Gebert, Boerner, Kearney, King Jr., Zhang, and Song (2014: 543) have called religion the "neglected diversity dimension" within the literature on workplace relationships and conflicts. ${ }^{1}$ However, research in this area has increased in recent years. 
The nascent literature on workplace religious discrimination generally divides into two categories. The first category consists of experimental audits. Several such experiments have shown that an individual is less likely to receive a job interview if his or her application indicates that he or she is a Muslim or an atheist (Wright, Wallace, Bailey, and Hyde 2013; Wallace, Wright, and Hyde 2014). Although it did not examine religion explicitly, another study (Widner and Chicoine 2011) found that applications with an "Arab-sounding name" were less likely to receive an interview, a finding which could also be linked to anti-Muslim biases.

Such experiments are strong in their ability to demonstrate what we might call objective or actual discrimination. Because of the experimental design we can be sure that employers truly did find some applicants more or less attractive based on the indicated religious identity. Such studies, however, are usually limited to a fairly narrow part of the employment process (i.e., application review) and do not tell us about individuals' broader experiences and perceptions of religious discrimination in the workplace.

A second type of research utilizes surveys to measure respondents' perceptions of their experiences with religious discrimination in the workplace. For example, Cragun, Kosmin, Keysar, Hammer, and Nielsen's (2012) survey of individuals identifying as non-religious found higher rates of perceived discrimination among self-identified atheists as compared to other nonreligious groups (e.g., agnostic). In a broader survey, Scheitle and Ecklund (2017) found that Muslims, Hindus, Jews, atheists, and evangelical Protestants perceived having experienced more religious discrimination than mainline Protestants, Catholics, and those identifying as not religious or agnostic. The frequency with which the respondent stated that religion comes up at work was also found to increase the likelihood of perceiving such discrimination. 
Note that such surveys do not necessarily measure what we might think of as actual discriminatory events in the same way that the audit studies. That is, a person might perceive discrimination when it did not actually occur based on some external evidence (and we acknowledge of course that discrimination can indeed occur in hard to document ways). Furthermore, these survey items are likely measuring a broad range of respondents' experiences, from interpersonal conflicts to discrimination in hiring or promotion. Despite their limitations, though, such surveys can be valuable in understanding individuals' perceptions of their workplace experiences, as those perceptions (whether accurate or not) could shape how individuals actually engage with religion in the midst of their careers, through their relationships with employers and coworkers.

\section{Perceptions of Religious Discrimination among Academic Scientists}

Although different in their methods and the nature of what they are measuring, the experimental and survey studies overlap in finding higher rates of actual or perceived discrimination among Muslims and atheists. This finding corresponds with research showing relatively negative attitudes towards these groups. Summarizing data from "feeling thermometer" scores included in the 2007 Faith Matters Survey, Putnam and Campbell (2010: 509; see also Pew Forum 2017) state that "[a]lmost everyone likes mainline Protestants and Jews...[a]lmost everyone likes Catholics...[and] [a]lmost everyone dislikes Muslims..." And Edgell, Gerteis and Hartmann (2006: 230) conclude based on their analysis of US survey data that "[a]theists are at the top of the list of groups that Americans find problematic in both public and private life, and the gap between acceptance of atheists and acceptance of other racial and religious minorities is large and persistent." 
PERCEPTIONS OF RELIGIOUS DISCRIMINATION

Occupations and employment sectors are diverse, however, and each presents its own conditions, cultures, and visions of the "ideal worker" (Trice 1993; Williams 2000; Ecklund 2010). Variations in occupational cultures may shape the experiences of any specific group in a particular workplace environment (Turco 2010). There are reasons to believe that the academic environment, particularly in the natural sciences, might present different social and cultural dynamics in regards to religion and religious discrimination (Yancey, Reimer, and O'Connell 2015).

For instance, surveys of professors have tended to find more favorable views of atheists and Muslims than what is found in the general public (Tobin and Weinberg 2007). Furthermore, as described earlier, the religious demographics of academic scientists are quite different from the US overall (Ecklund and Scheitle 2007; Gross and Simmons 2009; Ecklund 2010), which could lead to different patterns of discrimination, both actual and perceived. The general irreligiosity of many academic scientists could lead to an expectation that everyone is andlor should be irreligious. This assumption could lead to objective instances of discrimination against religious scientists. This assumption could also make it difficult for the religious to freely express themselves, and feeling like one must suppress part of his or her identity can actually produce feelings of discrimination independent of actual experiences (Madera, King, and Hebl 2012).

Much of the research on discrimination within the scientific community has focused on gender andlor race (Shenhav and Haberfeld 1988; Haberfeld and Shenhav 1990; Prokos and Padavic 2005). Religion, however, presents a relatively unexamined basis for discrimination among scientists. Such a gap in our understanding is consequential, as many people view the academy as politically liberal and hostile towards religion, positions that are often seen as two 
sides of the same coin. Indeed, research has demonstrated discrimination against religious and conservative individuals within the academy (Rothman, Lichter, and Nevitte 2005). For instance, in a survey of sociologists, Yancey (2011) found that job candidates are more likely to be viewed negatively if he or she was Mormon or a conservative Christian.

Here we examine perceptions of religious discrimination among physicists and biologists. These two disciplines were chosen for a number of reasons. For one, both disciplines are core natural-science disciplines, making them more natural to compare to each other than, say, physics and sociology. Also, most prominent research universities have departments of physics and biological sciences. Furthermore, both biology and physics have been active in current andlor historical conversations about religious and moral implications of scientific research. Physics has historically been ahead of the curve in fostering discussions about the moral implications of science, such as nuclear non-proliferation (Dooley and Kerch 2000) which, for some, have religious implications. Biology has been particularly embroiled in public debate concerning issues like human embryonic stem cell research and the teaching of evolution. At the same time, there are some key differences between the disciplines. For instance, the biology and physics have very different levels of female involvement, which may have an impact on how religion is framed within each discipline, since women are more likely than men to be religious (Miller and Stark 2002; Nelsen and Rizvi 1984).

\section{DATA AND METHODS}

The data used for this research comes from a survey of biologists and physicists employed at universities and research centers in the United States. This survey was part of a larger study which consisted of surveys and interviews with biologists and physicists in eight nations. ${ }^{2}$ We focus only on the United States data in this paper partly for practical purposes. 
Because each of the nations that were part of the project has its own religious context, not to mention scientific context, a single analysis and discussion of religious discrimination among scientists across eight nations is difficult to make coherent. This decision, however, is also based on the fact that contemporary debates and perceived conflicts between religion and science are arguably most salient in the United States, given its highly developed science infrastructure alongside it's large and influential religious population, compared to, for example, most Western European nations.

The sampling for the survey occurred in two stages. In the first stage a sampling frame of biology and physics departments was constructed and stratified by discipline and elite or nonelite status. The departments were identified by examining the affiliations of authors on articles we identified through the Web of Science (WOS) database for each of these disciplines. The WOS is a database that contains articles of over 12,000 scientific journals. We assume that research intensive organizations are well-represented in WOS journals. WOS also includes, however, many less research-intensive organizations, allowing our sampling frame of organizations to have ample variance in terms of research activity, representing a significant strength of this study. In addition, WOS provides non-university organizations that house research active biologists and physicists, another benefit that existing rankings fail to offer. We do acknowledge that our sampling procedure fails to capture organizations that have no scientists who publish research articles, something to keep in mind when interpreting statistical generalizations from our sample of scientists.

The WOS process identified 491 US departments (285 biology and 206 physics). We then stratified these by whether the department could be considered "elite" or not. In making this classification we relied largely on research output, National Research Council rankings and also 
PERCEPTIONS OF RELIGIOUS DISCRIMINATION

consulted well-established biologists and physicists at US universities. From this stratified sampling frame of departments we then selected 11 elite biology departments, 15 non-elite biology departments, 17 elite physics departments, and 35 non-elite physics departments. It was necessary to oversample some categories in order to get a large enough $\mathrm{N}$ because of small department sizes.

We then used departmental websites to construct a sampling frame of individuals within the selected departments. We stratified this frame by rank and gender. For rank, we separated identified individuals into three categories: 1) scientists in training (graduate students), 2) pretenure scientists who have finished their training (postdoctoral fellows, assistant professors), and 3) tenured scientists (associate and full professors). We then sampled 3,989 individuals, in some cases oversampling where a stratum had relatively few total cases. For instance, biology departments tend to have more individuals than physics departments, so we oversampled individuals in physics to increase the number of respondents. Sampling weights can be applied to return the distributions to that of the sample frame. For instance, when unweighted biologists represent $49 \%$ of our respondents, but when weighted they represent $66 \%$.

The survey itself was fielded by the survey firm Abt SRBI during the beginning of 2015 . Each sample member was sent a pre-notification letter and $\$ 5$ as an incentive. An email invitation was then sent to each potential respondent with a unique link to complete the survey online. Non-responders were then sent email reminders and then - if still not responding eventually the survey firm made a telephone call to request participation. In the end we received 1,989 completed responses. Our survey obtained a 57.1\% response rate using the American Association for Public Opinion Research's definition number 3 for response rates, which takes into account known ineligible cases and estimates eligibility among unknown cases. 
PERCEPTIONS OF RELIGIOUS DISCRIMINATION

\section{Dependent Variable}

Perceptions of discrimination. Our dependent variable comes from a question that asked the scientist respondents, "How often have you felt discriminated against in your work life as a scientist because of the following: Your religion." Responses offered were 1) Never, 2) Rarely, 3) Sometimes, 4) Often, 5) Very often. It is important to highlight that this question asks specifically about the respondent's "work life as a scientist" and not simply discrimination in all settings.

\section{Independent Variables}

Religious Identity, Practices, and Beliefs. We measure respondents' religious identity, practices, and beliefs in several ways. The first is a basic religious identity question asking, "Do you belong to a religion or religious denomination? If yes, which one?" Responses include "I do not belong to a religion," "Roman Catholic," "Protestant," "Jew," "Muslim," "Hindu," "Buddhist," "Other." In analyses of the US general population it is common to break the large Protestant category into smaller groups (e.g., Evangelical, Mainline, and sometimes Black Protestant). Only $11 \%$ of our respondents identify as Protestant, however, which is much smaller than the almost $50 \%$ found in the general population. The great majority of the Protestants in our data appeared to be relatively moderate or liberal compared to the general population. For instance, only $8 \%(\mathrm{~N}=13)$ of the Protestant scientists in our data stated that the Bible is the "Actual word of God and is to be taken literally, word for word." This compares to close to 50\% of Protestants in surveys of the general US adult population. Furthermore, to the extent conservative Protestants face greater discrimination within the scientific community, we would theoretically expect this to be a product of their greater religious practice andlor adherence to 
PERCEPTIONS OF RELIGIOUS DISCRIMINATION

particular beliefs. ${ }^{4}$ Given that we will also be including measures of religious practice and belief, we leave the Protestant category as is. ${ }^{5}$

We also include a question asking about the respondent's frequency of attendance at religious services. The question asked, "Apart from weddings and funerals, about how often do you attend religious services these days?" Seven responses were offered, ranging from 1) Never, practically never to 7) More than once a week. This measure will help assess whether it is religious identity alone that shapes discrimination risk among scientists, or whether it is the level of actual religious practice. Since religious service attendance is a more public measure of practice, we also include a variable measuring the respondents' frequency of prayer. This question asked, "Now thinking about the present, about how often do you pray?" Eleven responses were offered ranging from never to several times a day. In addition to representing a more private measure of religious practice, this measure might better reflect religious traditions in which prayer is a major component of practice for the tradition (e.g., Islam), potentially more so than congregational- or attendance-based practices.

Four measures of religious belief are included in the analysis. ${ }^{6}$ The first represents the respondent's view of the Bible. The question asked, "Which of these statements comes closest to describing your feelings about the Bible?" Possible responses were 1) The Bible is the actual word of God and is to be taken literally, word for word, 2) The Bible is the inspired word of God but not everything should be taken literally, word for word, 3) The Bible is an ancient book of fables, legends, history, and moral precepts recorded by man, 4) This does not apply to me, 5) Don't know. In preliminary analyses we kept all five of these responses separate. However, as mentioned earlier, very few respondents chose the first response ("actual word of God") and our analyses showed that we were not able to derive meaningful results from keeping that response 
separate. As a result, we combined the first and second response to represent individuals who stated that the Bible is the actual or inspired word of God. A second measure of belief represents the respondents answer to the question, "Please indicate which statement below comes closest to expressing what you believe about God." Possible responses were 1) I don't believe in God, 2) I don't know whether there is a God and I don't believe there is any way to find out, 3) I don't believe in a personal God, but I do believe in a Higher Power of some kind, 4) I find myself believing in God some of the time, but not at others, 5) While I have doubts, I feel that I do believe in God, 6) I know God really exists and I have no doubts about it.

We also include two items that assess what we expect to represent particularly problematic beliefs in a scientific context. The survey asked respondents to "Please indicate the extent to which you agree or disagree with the following statement. God performs miracles." Those that did not indicate any belief in God on a previous question were not asked this miracles question, so we code those individuals as strongly disagreeing that God performs miracles. ${ }^{7}$ We also include a measure from a question asking, "Human beings, as we know them today, developed from earlier species of animals.” Respondents could either say True, False or Don't Know. Because expressing doubt in evolution (i.e., Don't Know) would likely be seen as the same as rejecting evolution by many scientists, we combine the Don't Know category with the False category. This is obviously not explicitly a question about religion or religiosity, but views concerning the origin of life are often tied to religious views and religion often has an explicit role in anti-evolution advocacy efforts. Indeed, while just over 3\% of our scientist respondents chose false for this statement and just under 5\% said that they don't know, these respondents seem concentrated among those who report attending religious services more frequently, express certainty in their belief in God's existence, and describe themselves as a religious person. 
Another $8 \%$ of respondents did not answer this question, but these cases do not seem as strongly related to measures of religiosity. As a result, we treat these cases as "missing" and do not use them in the analysis below.

Other Respondent Characteristics. Religious identities can overlap with ethnic and immigrant identities. This makes it necessary to account for these characteristics when examining religious discrimination. ${ }^{8}$ Do Muslims, for instance, still report more religious discrimination even after the effect of ethnicity and immigrant status is accounted for? To address this issue, we include a series of dichotomous indicators from a question asking about the respondent's ethnicity. These indicators include CaucasianlWhitelEuropean, East Asian, South Asian, and Other. ${ }^{9}$ We also include a dichotomous indicator from a separate question asking whether the respondent is Hispanic.

Although research points to a more nuanced link between religious and political ideology (Stellway 1973; Smidt and Penning 1982; Malka, Lelkes, Srivastava, Cohen, and Miller 2012), religiosity could be seen by scientists as a rough proxy for conservative political views (or vice versa). This could be important given the increasing politicization of science and views of and towards scientists (Gauchat 2012). To account for this, we include a measure of the respondent's political ideology. The survey question representing this asked, "In political matters, people talk of 'the left' and 'the right.' Using a scale where ' 1 ' means 'left' and '10' means 'right,' how would you place your views on this scale, generally speaking?"

We include several other control measures, including sex, marital status, number of children ever had, and age. Age is measured continuously. ${ }^{10}$ Sex is measured as 0) Male and 1) Female. ${ }^{11}$ Marital status is represented by several dichotomous indicators for Married, Living together as Married, Divorced $\mid W i d o w e d I S e p a r a t e d$, and Single. ${ }^{12}$ The number of children comes 
PERCEPTIONS OF RELIGIOUS DISCRIMINATION

from a question asking, "How many children have you had?" Responses over three were collapsed into a "four or more" category. This measure in particular could be relevant to perceived religious discrimination since religiosity is often associated with fertility patterns (Mosher, Williams, and Johnson 1992; Hout, Greeley, and Wilde 2001; McQuillan 2004). To the extent that having more children is associated with or at least perceived to be associated with more religious scientists, this could represent a discrimination risk factor.

Descriptive statistics for all measures used in our analysis are shown in table 1 . We

removed cases with missing data on these measures unless otherwise described above. ${ }^{13}$ This left a final analytical sample of 1,773 scientists, with 870 in biology and 903 in physics.

\section{$<$ INSERT TABLE 1 ABOUT HERE>}

\section{RESULTS}

As seen in Table 1, 85.0\% of our scientist respondents report never experiencing religious discrimination. Of the $15.0 \%$ of scientists reporting at least some experience with religious discrimination, $10.1 \%$ say they rarely experience such discrimination, while $3.9 \%$ report sometimes experiencing discrimination, $0.3 \%$ say they often experience religious discrimination, and $0.7 \%$ say they very often experience religious discrimination. In Table 2 we present bivariate patterns of perceived discrimination by discipline and measures of religious identity, practice, and belief. For the sake of readability, the percentages in this table combine the rarely, sometimes, often, and very often responses so that they represent the percentage reporting at least some perception of discrimination.

We do not see much of any difference between biologists (14.8\%) and physicists (15.3\%) in the overall rate of perceiving at least some religious discrimination. There are, though, more substantial differences across religious traditions, practices, and beliefs. The least likely to report 
at least some experiences with religious discrimination are scientists who say they do not belong to a religion. Just over seven percent of this group report religious discrimination, which is about half the rate of the overall sample. At the other extreme, $63.6 \%$ of Muslim scientists report at least some religious discrimination, which is over four times the percentage for the whole sample. Scientists who say they are Protestant have the second highest percentage reporting some religious discrimination at $40.4 \%$. Scientists identifying as Jewish, Buddhist, Catholic, or as an other religion are somewhat higher than the overall rate of reported religious discrimination, while Hindu scientists are slightly lower. Comparing the religious identity patterns by discipline suggests that the effect of religious identity on perceptions of religious discrimination might be stronger among biologists. For instance, $26.6 \%$ of Jewish biologists report at least some perception of discrimination compared to $8.4 \%$ of Jewish physicists. Similarly, we see that $86.5 \%$ of Muslim biologists report at least some religious discrimination compared to $46.6 \%$ of Muslim physicists

Looking at the measures of religious practice, we see that those who attend religious services weekly or more and those who pray daily or more are much more likely to report religious discrimination than those that never attend or pray. This gap appears to be slightly larger among biologists than physicists. We find similar patterns when looking at the measures representing respondents' view of the Bible, belief in God, view of evolution, and opinion on miracles.

\section{<INSERT TABLE 2 ABOUT HERE>}

There are clearly many other potential variables that overlap with religious tradition, practices, and beliefs, such as ethnicity and race. Furthermore, religious identities, practices, and beliefs of course also overlap with one other. We turn to Table 3 to begin accounting for these 
issues and to identify independent effects of different measures of religiosity. This table shows the results of ordered logistic regression models predicting the frequency of perceived religious discrimination outcome as originally measured with the five responses of never, rarely, sometimes, often, and very often. The table presents odds ratios, so that numbers above one indicate increased perceptions of religious discrimination while those below one indicate reduced perceptions of religious discrimination. Models 1 through 3 show the results for the biologists, while Models 4 through 6 show the results for the physicists.

\section{Biologists}

Model 1 examines differences in perceptions of religious discrimination among biologists across the religious identity indicators. We see that, relative to biologists without a religious identity, biologists identifying as Catholic, Protestant, Jewish, Muslim, or as 'other' religious identity have significantly higher odds of perceiving religious discrimination. Although the odds ratios are in a similar direction for Hindu and Buddhist biologists, these differences are not statistically significant.

Model 2 adds the measures of religious practices and beliefs to the analysis. Although none of these religious belief or practice measures are themselves significant, accounting for them does weaken some of the differences seen across the religious identity indicators in Model 1. The difference between Catholic biologists and biologists without a religious identity is no longer significant when controlling for differences in religious beliefs and practices. However, Protestant, Jewish, Muslim, and 'other' biologists still have significantly higher odds of perceiving religious discrimination relative to biologists without a religious identity even after we account for their religious beliefs and practices. 
Model 3 adds measures of professional status and demographics to the analysis. These measures, though, do not explain away the higher odds of perceiving religious discrimination among Protestant, Jewish, and Muslim biologists relative to biologists without a religious identity. Being Protestant, Jewish, or Muslim appears to have a unique and independent impact on perceptions of religious discrimination among biologists. To put this another way, there appears to be something about simply holding these religious identities as a biologist that seems to foster perceptions of religious discrimination regardless of any specific religious beliefs, frequency of religious practice, or any professional or demographic factors.

We cannot be sure whether holding these religious identities leads to actual instances of discrimination among biologists, or whether holding these identities simply heightens biologists' fears of discrimination which, in turn, lead to greater perceptions of discrimination. It is possible, for example, that in workplace conversations a biologist reveals that he or she is Protestant, and that revelation leads to actual cases of discrimination. Alternatively, it is possible that a biologist holding these identities feels more pressure to suppress the identity, and this suppression by itself leads to perceptions of discrimination (Madera, King, and Hebl 2012).

Before moving to the results for physicists, it is worth pointing out that political conservatism is significantly associated with increased perceptions of religious discrimination among biologists. This suggests that a biologist's political conservatism could be seen as a proxy for religion or religiosity even when that scientist's actual religion or religiosity does not differ from another comparable biologist.

\section{Physicists}

Turning to physicists, Model 4 begins by just looking at the initial differences across religious identities. Similar to what was seen when looking at the biologists, physicists who 
identify as Protestant, Muslim, or with an 'other' religion have significantly higher odds of perceiving religious discrimination relative to physicists who do not identify with a religion. However, Catholic and Jewish physicists do not significantly differ from physicists who do not identify with a religion. Remember that these identities did produce significantly higher perceptions of religious discrimination among biologists (see Model 1).

Model 5 adds the measures of religious beliefs and practices to the analysis of physicists' perceptions of religious discrimination. We find that frequency of religious service attendance and prayer are both positively associated with perceptions of religious discrimination among physicists. Again, we cannot be sure whether the religious practices of physicists lead to actual cases of discrimination, or whether they simply heighten fears and, then, perceptions of discrimination. Attending religious services might increase requests of religious accommodations or simply reveal the extent of one's adherence above and beyond identification, both of which could lead to objective instances of discrimination. Or, such practices might simply make a physicist internally feel like he or she is at risk for discrimination, which could lead to heightened perceptions of discrimination (Madera, King, and Hebl 2012).

Probably of most interest is the fact that, after accounting for religious beliefs and practices, all of the religious identity differences in perceptions of religious discrimination among physicists become non-significant. This is different from what was found for biologists, as many of the religious identity effects remained significant in that analysis even after controlling for religious beliefs and practices (see Model 2).

Model 6 introduces the professional and demographic measures to the analysis of physicists' perceptions of religious discrimination. Both measures of religious practice remain significant positive predictors of these perceptions. As seen in Model 5, none of the religious 
identity indicators are significantly different from physicists who do not identify with a religion although the Muslim effect is very close to the specified significance level $(\mathrm{p}=.051)$.

To summarize the primary findings, differences in religious practice appear to drive many of the religious identity differences in perceptions of religious discrimination among physicists. Protestant physicists, for example, perceive more religious discrimination because they are more active in religious practices (i.e., religious service attendance, prayer) than physicists who do not identify with a religion. Among biologists, however, religious identity alone appears to contribute to perceptions of religious discrimination. Protestant biologists, for example, perceive more religious discrimination because they identify as Protestant, not because they are necessarily more active in religious practices than biologists who do not identify with a religion.

<INSERT TABLE 3 ABOUT HERE>

\section{DISCUSSION AND CONCLUSION}

Occupations, especially those that might be considered "professions," often entail the adoption and creation of an occupational or professional identity (Broadhead 1983; Niemi 1997; Pratt, Rockmann, and Kaufmann 2006; Helmich et al 2012). Usually contained within a professional identity is an implied membership and adherence to a group that is distinct in values, behaviors, and interests (Callero 1985; Ashforth and Mael 1989; Stets and Burke 2000). In short, a professional identity creates a boundary between members and non-members.

It is the boundary between scientist and non-scientist that a religious scientist may threaten (Gieryn 1983). By threatening this boundary (that a professional scientist is not religious), a religious scientist may experience actual instances of hostility and discrimination from his or her scientist co-workers. Even absent of actual hostility or discrimination, a religious 
scientist's awareness of this boundary might heighten his or her fears about experiencing such hostility and discrimination. These fears might lead him or her to perceive hostility and discrimination even when it is not actually happening.

Our analysis of biologists and physicists reveals that the dynamics associated with perceived religious discrimination differ by scientific discipline. Among biologists, simply holding some religious identities is associated with increased perceptions of religious discrimination. In particular, identifying as Protestant, Jewish, or Muslim is associated with more perceived discrimination regardless of religious beliefs or practices. Among physicists, though, identifying as Protestant, Muslim, or with an 'other' religion is associated with increased perceptions of religious discrimination simply because it overlaps with greater religious practice. In other words, identifying as, say, Protestant would not be expected to increase a physicists' perceptions of religious discrimination absent actual religious practice.

These disciplinary differences could suggest that the line between "us" and "them" is different for biologists and physicists. For biologists, simply identifying with certain religious traditions might violate the professional norm and move a biologist from "us" to "them." For physicists, though, it might be seen as acceptable to simply hold a religious identity. Practicing that religion, however, might threaten the professional norm and move a physicist from "us" to "them." We speculate that these different standards could be due to a long and on-going history of battles involving religion and the biological sciences (e.g., human embryonic stem cell research, teaching of evolution). Some religious groups, like Protestants and Muslims, might be seen by biologists as groups that take their religion more seriously in terms of practice and religions that may have implications for science (Gilkey 1985; Binder 2002; Gibson 2004; Scott 2009). So, individuals who identify with those groups, regardless of their practices or beliefs, 
might be subject to or at least perceive more hostility. Such battles might be less salient among physicists, allowing individuals to at least hold such identities.

As is always the case, there are limitations to these findings. First, as stated from the beginning, our measure represents perceptions of religious discrimination. We cannot be sure whether what a respondent reports as an instance of religious discrimination is real from some objective standard. Future researchers ought to examine how tightly linked perceptions of religious discrimination are to actual experiences of discrimination. We also do not know the nature of the perceived discrimination experienced by the respondent. Was it in regards to hiring? A request for accommodation? Day-to-day interpersonal treatment?

We also cannot be sure of when the perceived religious discrimination occurred or if it is still occurring. Our survey asked about religious discrimination specifically in the respondents' "work life as a scientist" and the religion effects we report remain after accounting for respondents' age and professional rank. Still, there is some lack of certainty whether the perceived discrimination occurred in the last week, month, year, or many years ago.

Although the biology's and physics' shared status as core natural science disciplines provides some advantages for the purposes of comparison, the fact that our data only focused on these disciplines also means that we do not know how the findings presented here would differ if looking at other academic fields. For instance, it is possible that a field like psychology would be even more challenging for a religious scientist, as professors in that field have particularly low rates of religiosity. On the other hand, health-related fields might present a more welcoming environment given the relatively higher levels of religiosity among professors in those fields (Gross and Simmons 2009). Still, this is speculation and more research would be needed to make such conclusions. 
Despite these limitations, this research highlights issues that need to be taken into account as science tries to improve its diversity and the university - and science itself - seeks to negotiate and, in many cases, improve its relationship with members of the public that on the whole is more religious than most professors. 


\section{REFERENCES}

Aquino, Karl, Steven L. Grover, Murray Bradfield, and David G. Allen. 1999. The effects of negative affectivity, hierarchical status, and self-determination on workplace victimization. Academic of Management Journal 42(3): 260-72.

Ashforth, Blake E. and Fred Mael. 1989. Social identity theory and the organization. Academy of Management Review 14(1): 20-39.

Binder, Amy J. 2002. Contentious curricula: Afrocentrism and creationism in American public schools. Princeton University Press.

Bowling, Nathan A. and Terry A. Beehr. 2006. Workplace harassment from the victim's perspective: A theoretical model and meta-analysis. Journal of Applied Psychology 91(5): 998-1012.

Broadhead, Robert S. 1983. The private lives and professional identity of medical students. New Brunswick, NJ: Transaction Books.

Callero, Peter L. 1985. Role-identity salience. Social Psychology Quarterly 48(3): 203-15.

Cragun, Ryan T., Barry Kosmin, Ariela Keysar, Joseph H. Hammer, and Michael Nielsen. 2012. On the receiving end: Discrimination toward the non-religious in the United States. Journal of Contemporary Religion 27(1): 105-27.

Dooley, James J. and Helen M. Kerch. 2000. Evolving research misconduct policies and their significance for physical scientists. Science and Engineering Ethics 6(1):109-21.

Ecklund, Elaine Howard. 2010. Science vs. religion: What scientists really think. New York: Oxford University Press.

Ecklund, Elaine Howard and Christopher P. Scheitle. 2007. Religion among academic scientists: Distinctions, disciplines, and demographics. Social Problems 54(2): 289-307. 
Edgell, Penny, Joseph Gerteis, and Douglas Hartmann. 2006. Atheists as 'other': Moral boundaries and cultural membership in American society. American Sociological Review 71(2): 211-34.

Emerson, Michael O., Christian Smith, and David Sikkink. 1999. Equal in Christ, but not in the world: White conservative Protestants and explanations of black-white inequality. Social Problems 46(3): 398-417.

Gauchat, Gordon. 2012. Politicization of science in the public sphere: A study of public trust in the United States, 1974 to 2010. American Sociological Review 77(2): 167-87.

Gebert, Diether, Sabine Boerner, Eric Kearney, James E. King Jr., Kai Zhang, and Lynda Jiwen Song. 2014. Expressing religious identities in the workplace: Analyzing a neglected diversity dimension. Human Relations 67(5): 543-63.

Gibson, M. Troy. 2004. Culture wars in state education policy: A look at the relative treatment of evolutionary theory in state science standards. Social Science Quarterly 85(5):1129-49.

Gieryn, Thomas F. 1983. Boundary-work and the demarcation of science from non-science: Strains and interests in professional ideologies of scientists. American Sociological Review 48(6): 781-95.

Gilkey, Langdon. 1985. Creationism on trial: Evolution and god at Little Rock. Charlottesville: University Press of Virginia.

Gross, Neil and Solon Simmons. 2009. The religiosity of American college and university professors. Sociology of Religion 70(2): 101-29.

Haberfeld, Yitchak and Yehouda Shenhav. 1990. Are women and blacks closing the gap? Salary discrimination in American science during the 1970s and 1980s. Industrial and Labor Relations Review 44(1): 68-82. 
Harris, Gardiner. 2009. For N.I.H. chief, issues of identity and culture. The New York Times, October $9^{\text {th }}$.

Helmich, Esther, Sanneke Bolhuis, Tim Dornan, Roland Laan and Raymond Koopmans. 2012. Entering medical practice for the very first time: Emotional Talk, meaning and identity development. Medical Education 46(11): 1074-86.

Hinojosa, Victor J. and Jerry Z. Park. 2004. Religion and the paradox of racial inequality attitudes. Journal for the Scientific Study of Religion 43(2): 229-38.

Hout, Michael, Andrew Greeley, and Melissa J. Wilde. 2001. The demographic imperative in religious change in the United States. American Journal of Sociology 107(2): 468-500.

Madera, Juan M., Eden B. King, and Michelle R. Hebl. 2012. Bringing social identity to work: The influence of manifestation and suppression on perceived discrimination, job satisfaction, and turnover intentions. Cultural Diversity and Ethnic Minority Psychology 18(2): $165-70$.

Malka, Ariel, Yphtach Lelkes, Sanjay Srivastava, Adam B. Cohen, and Dale T. Miller. 2012. The association of religiosity and political conservatism: The role of political engagement. Political Psychology 33(2): 275-99.

McQuillan, Kevin. 2004. When does religion influence fertility? Population and Development Review 30(1): 25-56.

Miller, Alan S. and Rodney Stark. 2002. Gender and religiousness: Can socialization Explanations Be Saved? American Journal of Sociology 107(6): 1399-1423.

Mosher, William D., Linda B. Williams, and David P. Johnson. 1992. Religion and fertility in the United States: New patterns. Demography 29(2): 199-214 
PERCEPTIONS OF RELIGIOUS DISCRIMINATION

Nelsen, Hart M. and Arshad Rizvi. 1984. Gender and religious socialization: Comparisons from Pakistan and the United States. Journal of Comparative Family Studies 15(2): 281-90.

Niemi, Päivi M. 1997. Medical students' professional identity: Self-reflection during the preclinical years. Medical Education 31(6): 408-15.

Pew Forum. 2017. Americans express increasingly warm feelings toward religious groups. Pew Research Center: Religion \& Public Life. Accessed at www.pewforum.org on September $14,2017$.

Pratt, Michael G., Kevin W. Rockmann, and Jeffrey B. Kaufmann. 2006. Constructing professional identity: The role of work and identity learning cycles in the customization of identity among medical residents. Academy of Management Journal 49(2): 235-62.

Prokos, Anastasia and Irene Padavic. 2005. An examination of competing explanations for the pay gap among scientists. Gender \& Society 19(4): 523-43.

Putnam, Robert D. and David E. Campbell. 2010. American grace: How religion divides and unites us. New York: Simon \& Schuster.

Rios, Kimberly, Zhen Hadassah Cheng, Rebecca R. Totton, and Azim F. Shariff. 2015. Negative stereotypes cause Christians to underperform in and disidentify with science. Social Psychological and Personality Science 6(8): 959-67.

Rothman, Stanley, S. Robert Lichter, and Neil Nevitte. 2005. Politics and professional advancement among college faculty. The Forum 3(1): 1-16.

Scheitle, Christopher P. and Elaine Howard Ecklund. 2017. Examining the effects of exposure to religion in the workplace on perceptions of religious discrimination. Review of Religious Research 59(1): 1-20. 
Scott, Eugenie C. 2009. Evolution vs. creationism: An introduction. Westport, CT: Greenwood Press.

Shenhav, Yehouda A. and Yitchak Haberfeld. 1988. Scientists in organizations: Discrimination processes in an internal labor market. The Sociological Quarterly 29(3): 451-62.

Smidt, Corwin and James M. Penning. 1982. Religious commitment, political conservatism, and political and social tolerance in the United States: A longitudinal analysis. Sociological Analysis 43(3): 231-46.

Stellway, Richard J. 1973. The correspondence between religious orientation and socio-political liberalism and conservatism. The Sociological Quarterly 14(30: 430-39.

Stets, Jan E. and Peter J. Burke. 2000. Identity theory and social identity theory. Social Psychology Quarterly 63(3): 224-37.

Tobin, Gary A. and Aryeh K. Weinberg. 2007. Profiles of the American university: Religious beliefs \& behavior of college faculty. San Francisco: Institute for Jewish \& Community Research.

Trice, Harrison M. 1993. Occupational subcultures in the workplace. Ithaca, NY: Cornell University Press.

Turco, Catherine J. 2010. Cultural foundations of tokenism: Evidence from the leveraged buyout industry. American Sociological Review 75(6): 894-913.

Wallace, Michael, Bradley R.E. Wright, and Allen Hyde. 2014. Religious affiliation and hiring discrimination in the American south: A field experiment. Social Currents 1(2): 189-207.

Widner, Daniel and Stephen Chicoine. 2011. It's all in the name: Employment discrimination against Arab Americans. Sociological Forum 26(4): 806-23. 
Williams, Joan C. 2000. Unbending gender: Why family and work conflict and what to do about it. New York: Oxford University

Wright, Bradley R.E., Michael Wallace, John Bailey, and Allen Hyde. 2013. Religious affiliation and hiring discrimination in New England: A field experiment. Research in Social Stratification and Mobility 34: 111-26.

Yancey, George. 2011. Compromising scholarship: Religious and political bias in American higher education. Waco, TX: Baylor University Press.

Yancey, George, Sam Reimer, and Jake O’Connell. 2015. How academics view conservative Protestants. Sociology of Religion 76(3): 315-33. 


\section{ENDNOTES}

${ }^{1}$ There is a literature on how religion shapes attitudes about the role of discrimination in producing social and economic inequality (Emerson, Smith, and Sikkink 1999; Hinojosa and Park 2004).

${ }^{2}$ In addition to the United States, parallel surveys were conducted in France, Italy, Turkey, Hong Kong, Taiwan, India, and the United Kingdom.

${ }^{3}$ The survey did offer a distinct Orthodox response category. However, during our analyses we found that there were not enough cases to include this category separately in our models. As a result, we placed these cases in the Other category. If respondents selected the Other response, they were asked to specify what religion they belong to in an open ended question. Examining these responses shows this to be a very diverse category. It includes straight-forward responses like "Unitarian-Universalists" and "Mormon," but it also includes responses that were fairly detailed descriptions of syncretic beliefs or how the respondent views herself as, for example, “culturally" aligned with a religious tradition but not religious or not practicing. Given the complexity of such responses it is difficult to refine this category, which also makes it difficult to interpret it in the analyses.

${ }^{4}$ Many individuals, especially the religiously unaffiliated ones that comprise a large portion of our scientist respondents, likely would not recognize or appreciate a difference between a colleague who says they belong to a Lutheran Church-Missouri Synod congregation (typically classified as conservative Protestant) versus a colleague who says they attend an Evangelical Lutheran Church in America congregation (typically classified as mainline or liberal-moderate Protestant). They might, however, recognize the difference between a Protestant who says they 
attend church every Sunday versus one who does not or a Protestant who states a conservative theological belief versus someone who does not.

${ }^{5}$ In descriptive analyses we did look to see if Protestants who identified as conservative or liberal differed in reports of religious discrimination. The pattern was somewhat inconsistent and all of the categories were higher than the overall sample rate of $15 \%$. For instance, $27 \%(\mathrm{~N}=11)$ of Protestants identifying as "very conservative/traditional" reported at least some religious discrimination. This compares to $60 \%(\mathrm{~N}=28)$ of those identifying as "somewhat conservative/traditional," $36 \%(\mathrm{~N}=54)$ of those "somewhat liberal/progressive," $28 \%(\mathrm{~N}=78)$ of those "very liberal/progressive," and 56\% $(\mathrm{N}=30)$ of Protestants who said that "the terms conservative/traditional and liberal/progressive don't mean anything to me in this religious context."

${ }^{6}$ To assess potential issues with multicollinearity, particularly for the multiple measures of religiosity, we assessed the variance inflation factors (VIFs) for all of the measures utilized in our analysis. The mean VIF for the biologist model was 1.97 and the mean VIF for the physics model was 2.37. None of the VIFs were above 5.00 and all of the religion measures were below 4.00. These are all below commonly suggested standards for being concerned about multicollinearity.

${ }^{7}$ Both a "Have no opinion" and "Don't know" response option were offered. We combine these into the mid-point category.

${ }^{8}$ Descriptive analyses found that Black/African/Caribbean and Central Asian/Asian respondents were more likely to report at least some experience with religious discrimination (32\% and 44\%, respectively, compared to $15 \%$ among all respondents). These differences, of course, likely overlap with religious differences. 
${ }^{9}$ The survey question asked, "Please say which of these best describes your ethnicity." A category for Black\African\Caribbean and for Central Asian\Arab was merged into the Other category due to the small number of cases in each (28 and 21, respectively). The survey offered China, Japanese, Korean, and Taiwanese as examples for East Asian. For South Asian, the examples of Indian, Pakistani, and Bangladeshi were offered.

${ }^{10}$ A sizable number of respondents did not report a year of birth, which was used to compute age $(\mathrm{N}=176,8.4 \%)$. Rather than exclude these cases from the analysis, we replace each with the average age at the respondent's professional rank. For instance, those who did not provide an age and reported their rank as an assistant professor were given the average assistant professor age of 39.9. The other values assigned were 27.52 for graduate students, 33.52 for postdoctoral researchers, 47.97 for associate professors, 58.46 for full professors, 64.67 for full professors with named chairs, and 47.95 for those with other professional titles.

${ }^{11}$ About $8 \%$ of cases $(\mathrm{N}=160)$ did not provide a sex on the survey itself. In the construction of the individual-level sampling frame, however, each case's sex was coded if possible based on the name andlor photograph found on the department website. Rather than treat those who did not indicate their sex on the survey as missing, we assign the sex that was coded from the sampling frame, unless the individual's sex was also unclassified in the frame. In comparing the sample frame coding to the survey response for those cases in which we have both, we found that the sample frame coding was accurate $96.02 \%$ of the time for females and $99.01 \%$ for males. Six percent of the cases were not able to be categorized in this way due to lack of information or clarity in the sample frame coding. These cases are excluded in the analysis. A transgender response category was also offered on the survey, which four respondents chose. Since this is 
such a small number of cases and it does not seem appropriate to assign them to either male or female, we exclude these from the analysis.

${ }^{12}$ Divorced, widowed, and separated were separate response categories. However, due to the relatively small number of cases in these (40 for divorced, 13 each for widowed and separated), we combine them into one group for the analysis.

13 The race and ethnicity question was the largest source of missing information. 